\title{
Health professionals have an ethical duty ...
}

Alan Williams Centre for Health Economics, University of York

\section{New testament}

The British Medical Association (BMA) recently published guidance from its medical ethics committee on decision making concerning the withholding and withdrawing of life-prolonging medical treatment. ${ }^{1}$ It is a very thoughtful and thought-provoking document, the ramifications of which go far beyond the immediate situation it is addressing. The authors are clearly well aware of this. When considering a doctor's ethical response to "contemporaneous requests for life-prolonging treatment" made by competent patients, the committee observes:

“Although patients' wishes should always be discussed with them, the fact that a patient has requested a particular treatment does not mean that it must always be provided."'

They advance four propositions in support of this conclusion, namely:

“(a) Health professionals are not obliged to provide any treatment which cannot produce the desired benefit". ${ }^{3}$

"(b) There is no obligation to provide any treatment which is clearly contrary to an individual's health interests. A life-prolonging treatment may, for example, prolong life but result in severe pain or loss of function so that overall it produces severe harm to the patient". ${ }^{4}$

"(c) Except in an emergency situation, doctors are not obliged to treat contrary to their conscience (though they may be obliged to make an appropriate referral)". ${ }^{4}$

"(d) Where resources are limited, it is inevitable that some patients will not receive all of the treatment they request even though such treatment could be potentially beneficial to them". ${ }^{4}$

Towards the end of their commentary on the last of these propositions, they observe:

"Health professionals have an ethical duty to make the best use of the available resources and this means that hard decisions must be made.
Whilst this is a much broader issue than can be discussed thoroughly in this document, it is clear that doctors are not obliged to comply with patients' requests for treatment when they make inequitable demands on scarce resources".

Later they come back to this issue in the context of patients who have lost or never attained competence. In that connection they observe:

"Existing guidelines and court judgments have insisted that non-treatment decisions for people who lack the ability to make or communicate decisions should be based on considerations of benefit to the patient and not cost. It is obvious, however, that money spent caring for irreversibly and severely brain-damaged patients is money which cannot be used to treat other patients. This is an issue which needs to be acknowledged and addressed on a national scale as part of the debate on rationing and prioritising resources". ${ }^{6}$

\section{Exegesis}

Taking these propositions one by one, and scrutinising them a little more closely, the following intricacies come to light:

a) On the face of it this appears to be no more than the assertion that there is no obligation to do things that are ineffective. But failure to produce the "desired" benefit is not the same as failure to produce any benefit. The measurement and valuation of benefit depends on the perspective adopted. What the patient values, what the patient's nearest and dearest value, what the doctor values, what management values, and what the general public values, may all be different. In the present context it appears that the point being made is that the specific outcome that the patient wants is something that the experts know cannot be delivered by the treatment in question. But what if the treatment would deliver some appreciable benefit from society's viewpoint, but not enough to satisfy the patient? For instance, the treatment might eventually make 
the patient sufficiently independent to leave hospital and move to a nursing home, but the patient wants only to be independent enough to return home and manage there even without an informal carer, and the experts know that this is impossible. In such circumstances should the treatment be withheld because it fails to meet the patient's quite unrealistic expectations? Or is the acid test the potential benefits as valued by someone who does have realistic expectations? Is it perhaps the expert who thinks that the benefits will be insufficiently desirable to be worthwhile? If so, (a) can be subsumed under (d). Until we know who is doing the desiring, it is difficult to interpret this case.

b) Here "an individual's health interests" are distinguished from an individual's wishes. Presumably an individual's interests are being judged by a third party whose wishes override those of the patient. This cannot be happening because of ignorance on the part of the patient, because we are here dealing with competent patients who can presumably assimilate the relevant information. It must therefore be due to the value system of the patient being replaced by somebody else's value system (the doctor's, the society's?). The specific example given suggests that the prospect with treatment is for the patient to be left in a health state which the third party regards as being worse than being dead, but which the patient does not. So it is a simple case of whose values shall count. Presumably in the converse case it would be held that if the patient wished to die but the third party did not think that the situation was that bad, the patient's values would again be overridden. I am a little surprised by this position in the case of competent patients.

c) I have nothing worthwhile to say on the subject of conscientious objection to some treatments on the part of some doctors, except to observe that it should be acknowledged that there is also conscientious objection to some treatments among some patients.

d) The initial phrase "where resources are limited" seems redundant, since resources are always limited. But it is interesting to note that whereas the earlier propositions were about what doctors' obligations were, statement (d) simply refers to the inevitability of the fact that patients will not always get what they want even when it is potentially beneficial to them. This lack of moral content is remedied a little later with the assertion that health professionals have an ethical duty to make the best use of the available resources. Most people would interpret this to mean that they have an obligation to be efficient, in the high level sense of ensuring that health gains are maximised. But here the best use of resources is held to justify the disqualification of patients who make "inequitable" demands on scarce resources, thus shifting the ground into the field of distributive justice.

The final paragraph quoted above says no more than that costs and benefits must be systematically compared, and weighed one against the other, and that it is just as unethical to concentrate on benefits and ignore costs, as it is to concentrate on costs and ignore benefits. Quite so. This is an issue which needs to be acknowledged and addressed on a national scale as part of the debate on rationing and prioritising resources. Again, quite so. I think it would be a great service to the citizenry of the UK if the BMA's ethics committee would itself offer a substantial contribution to that debate, especially if it were as thoughtful and even-handed as this one. Assuming that they will in fact rise to the occasion, I would like to offer them some gratuitous advice!

My advice is prompted by a desire to refine the following nuggets extracted from the material cited above:

1) The benefits of health care comprise improvements both in the length and in the quality of people's lives, and each may be traded off against the other. This sounds remarkably like scene-setting for the QALY (Quality Adjusted Life Years) as a measure of health benefit.

2) The valuation of such benefits does not have to come from individual current patients. I would argue that in a tax-financed system serving the entire population, the relevant source of valuations should be the general citizenry, each of whom will have to weigh up the conflict they face individually between their role as potential patients and their role as actual taxpayers.

3) Opportunity costs are a key element in all this, both from an efficiency and from an equity standpoint, since they represent the health benefits foregone by those who did not get treated. This looks like scene-setting for costper-QALY calculations with equity weights.

4) The systematic comparison of costs and benefits is the crux of the matter. Read on ........

\section{Proselytising}

There is more to cost-benefit analysis than generalised discussion of advantages and disadvantages. It represents the outcome of much hard thinking 
about what is involved when we seek a systematic answer to the question: do the benefits of a certain action outweigh its costs? It proves to be very difficult even to formulate the question satisfactorily, and attempting to answer it frequently impresses one with the vast area of ignorance that pervades even quite commonplace activities. At that stage, therefore, the weak-spirited usually abandon the cost-benefit approach as too demanding, and return with relief to more comfortable ways.

The trouble with the more comfortable ways is that they foster the illusion that, if cost-benefit analysis is not done, the issues which it poses can be avoided, whereas the reality is that these issues are still present, and they all still have to be resolved. If health services planning is not to be based on the principle that unwitting decisions are likely to be better than witting decisions, then the cost-benefit approach must become part of every decision maker's intellectual equipment.

As a homely contribution to the furtherance of that worthy cause, I offer the following "checklist" of basic questions that should be asked every time anyone makes a studied recommendation about the use of resources. If it is impossible even to discern any material relevant to the questions, be especially on your guard, since the questions will have been answered by making assumptions, which may be unrealistic and/or unsupportable and/or unacceptable.

A basic check-list of questions runs as follows:

1. What precisely was the question that the study was trying to answer?

2. What is the question that it has actually answered?

3. What are the assumed objectives of the activity studied?

4. By what measures are these represented?

5. How are they weighted?

6. Do they enable us to tell whether the objectives are being attained?

7. What range of options was considered?

8. What other options might there have been?

9. Were they rejected, or not considered, for good reason?

10. Would their inclusion have been likely to change the results?

11. Is anyone likely to be affected who has not been considered in the analysis?

12. If so, why are they excluded?

13. Does the notion of cost go wider or deeper than the expenditure of the agency concerned?

14. If not, is it clear that these expenditures cover all the resources used, and accurately represent their value if released for other uses?
15. If so, is the line drawn so as to include all potential beneficiaries and losers, and are the resources costed at their value in their best alternative use?

16. Is the differential timing of the items in the streams of benefits and costs suitably taken care of (for example, by discounting, and, if so, at what rate)?

17. Where there is uncertainty, or there are known margins of error, is it made clear how sensitive the outcome is to these elements?

18. Are the results, on balance, good enough for the job in hand?

19. Has anyone else done better?

The last two have been added because I do not want to be accused of advocating a counsel of perfection. Decisions have to be made, and will continue to be made, on the basis of imperfect knowledge. But I am anxious to ensure that we know how little we know when we do what we have to do.

\section{Postscript}

Everything in that preceding section was taken word for word from an article I published in the British Medical Bulletin ${ }^{7}$ twenty-five years ago, which was recently republished, together with other neglected pearls of wisdom, in a book of essays entitled Being Reasonable about the Economics of Health. ${ }^{8}$ My apologies to any of you who have all that engraved on your heart, but it seems to me that there are still many people grappling with priority-setting issues who seem quite unaware of what they are getting into and where they might turn for help. Amongst the far-sighted people who appreciated the centrality of these issues a quarter of a century ago were Douglas Black, Archie Cochrane and Bryan Jennett. They deserve great credit for helping to ensure that what were then regarded as rather outrageously heretical views, about the role of economics in relation to the practice of medicine, continued to be brought to the notice of their colleagues. Even then they were of the view that health professionals have an ethical duty to make the best use of the available resources, but that they needed help in doing so.

There are, however, still many people who seem to believe that there is something fundamentally unethical about bringing economic appraisal techniques to bear on health care priority setting, at both the clinical and the planning levels. Concerning these ethical implications, I have observed elsewhere ${ }^{9}$ that:

"the evaluation of health care activities is an ethical minefield, strewn with explosive material not 
easily detected by the naked eye, but .... bringing this material out into the open and analysing it (both by logical discourse and by empirical enquiry) is an important extension of the analyst's role. I think it is our duty to rush in where others fear to tread, even if in the process we find ourselves being maligned as insensitive troublemakers, and even if the misguided criticise our analytical techniques because they require quite strong ethical assumptions to be made. It is not that any of these analytical techniques are ethical or unethical per se, it is more a matter of ensuring that their particular assumptions are appropriate in the context in which they are being used."10

Thus one cannot but welcome even-handed reviews of the strengths and weakness of the QALY approach to the evaluation of health care such as those produced recently by the Ethical QALY Group ${ }^{11}$ and by McKie et al. ${ }^{12}$ But the proof of the pudding is in the eating, and in the UK we shall soon discover how much real progress has been made in winning hearts and minds by the performance (and impact) of the National Institute for Clinical Excellence (and
Cost-effectiveness)? If it is successful in prioritising health care according to cost-effectiveness principles, 25 years will not have been too long to wait ......

Alan Williams is Professor of Economics at the Centre for Health Economics, the University of York.

\section{References}

1 British Medical Association. Withholding or withdrawing lifeprolonging medical treatment: guidance for decision making. London:British Medical Association, BMJ Books, 1999.

2 See reference 1: 17-18.

3 See reference 1: 18

4 See reference 1: 19 .

5 See reference $1: 20$

6 See reference 1: 49 .

7 Williams A. The cost-benefit approach. British Medical Bulletin 1974;30,3:252-6.

8 Culyer AJ, Maynard AK, eds. Being reasonable about the economics of health: selected essays by Alan Williams. Cheltenham England and Lyme USA: Edward Elgar, 1997: 26-37.

9 Williams A. Cost effectiveness analysis: is it ethical? fournal of Medical Ethics 1992;18,1: 7-11. This has also been reprinted in the book cited in reference 8: 296-304.

10 See reference 9: 11 and reference 8: 304.

11 Edgar A, Salek S, Shickle D, Cohen D. The ethical QALY: ethical issues in healthcare resource allocation. Haslemere Surrey: Euromed Communications, 1998

12 McKie J, Richardson J, Singer P, Kuhse H. The allocation of health care resources: an ethical evaluation of the QALY approach Dartmouth: Ashgate, 1998. 